\title{
Knowledge and Beliefs about Smoking among Urban African Americans with Type 2 Diabetes: A Qualitative Inquiry
}

Janet L. Thomas, Ph.D. ${ }^{1,2}$, Diana W. Stewart, B.A. ${ }^{3}$, Christine Makosky Daley, Ph.D. ${ }^{4}$, Christie A. Befort, Ph.D. ${ }^{4}$, Aimee S. James, M.P.H., Ph.D. ${ }^{4}$, Patricia M. Snow, M.P.H. ${ }^{4}$, Robyn M. Scherber, M.P.H. ${ }^{1}$, Jasjit S. Ahluwalia, M.D., M.P.H., M.S. ${ }^{1,2,5}$

${ }^{1}$ University of Minnesota Medical School, Department of Medicine, Minneapolis, MN

${ }^{2}$ University of Minnesota Cancer Center, Minneapolis, MN

${ }^{3}$ Louisiana State University, Department of Psychology, Baton Rouge, LA

${ }^{4}$ University of Kansas Medical Center, Department of Preventive Medicine, Kansas City, KS

${ }^{5}$ University of Minnesota, Academic Health Centers, Office of Clinical Research, Minneapolis, MN

\begin{abstract}
Background. Despite elevated risks of cardiovascular disease among African Americans with diabetes, few investigators have examined beliefs about cigarette smoking and smoking cessation among this underserved population.

Methods. Focus groups $(\mathrm{n}=4)$ and a short survey were used to assess cigarette use patterns, perceived smoking health effects, preferences for treatment, and attitudes toward smoking cessation among low income, African American smokers with type 2 diabetes.

Results. Participants $(\mathrm{n}=25, \mathrm{M}=48.5$ years $[ \pm 10.23], 60 \%$ female $)$ smoked $20.9( \pm 12.54)$ cigarettes per day $(\mathrm{CPD})$ and had on average $3.2( \pm 6.12)$ 24-hour quit attempts in the past year. Few had used clinic support or pharmacotherapy in their quit attempts. Participants smoked to control health-related stress, keep their appetite down, and to control their glucose.

Conclusion. The results suggested that African American smokers with diabetes may be an appropriate group to target for smoking cessation. Cessation recommendations are discussed. KJM 2009; 2(2):20-32.
\end{abstract}

\section{Introduction}

Cigarette smoking is the single most important preventable cause of morbidity, mortality, and excess health costs in the United States, accounting for approximately 427,000 deaths each year. ${ }^{1,2}$ Despite considerable prevention and intervention efforts, approximately 50 million US adults continue to smoke cigarettes, ${ }^{3,4}$ including 5.2 million African Americans (AA)., ${ }^{5,6}$ Groups with high prevalence rates of smoking include AA men, and those with lower levels of education and socioeconomic status. ${ }^{4,-11}$ While African Americans tend to smoke fewer cigarettes per day ${ }^{12}$ and begin smoking later in life ${ }^{13,14}$ than other groups in the US, they bear a disproportionate share of tobacco-related disease. $^{6,15}$ When compared to European Americans, AAs have the highest incidence rates for all cancers combined, ${ }^{6,15}$ are at elevated risk for cerebrovascular ${ }^{16}$ and heart disease, ${ }^{17,18}$ and have twice the rates of premature death attributable to cardiovascular disease. ${ }^{4,8}$

According to the National Institute of Health, the total prevalence of diabetes among non-hispanic whites is $8.7 \%$. African Americans have disproportionately higher rates (i.e., 13.3\%). ${ }^{19}$ Diabetes is associated with a substantial increase in the risk of cardiovascular disease (CVD) and this risk is increased further by cigarette smoking. Smokers with diabetes have an estimated two- to three- fold increase in the 
risk of cardiovascular complications compared to smokers without diabetes. ${ }^{20,21}$ The cardiovascular risks of smoking and diabetes in combination are nearly 14 times higher than the risk of either smoking or diabetes alone, much greater than expected from the simple combination of smoking and diabetes. $^{22}$ Smoking also substantially increases the risk for additional diabetesrelated complications including the development of hypertension and microvascular complications (e.g., neuropathy, nephropathy, and microalbuminuria). ${ }^{21,23,24}$ Despite these alarming statistics, the prevalence of smoking among persons with diabetes appears to mirror that among the general population. $^{25}$

Results from recent studies showed that smoking cessation results in substantial reduction in the risk of smoking-related morbidity and mortality; however, few smoking cessation intervention programs or research studies have focused exclusively on smokers with diabetes. ${ }^{26-29}$ Whether this is the result of concern that smoking cessation may compromise diabetes self-management efforts, the belief that patients with diabetes may not be interested in quitting, or limited awareness of the effectiveness of smoking cessation programs, is not clear. Research to date suggested that persons with diabetes may be less likely to quit smoking on their own than other smokers and may be more likely to fail in organized smoking cessation programs. $^{21,25}$

Recently, Hokanson and colleagues ${ }^{30}$ completed a randomized, controlled smoking cessation trial with 114 participants with type 2 diabetes. The results indicated that an intensive cessation intervention integrating face-to-face motivational interviewing plus telephone counseling into a standard diabetes self-management training program resulted in a trend toward greater abstinence at three months when compared to standard care. Although this trend was not observed at the six-month follow-up, the integration of smoking cessation into an existing diabetes education program did not impact diabetes management negatively, including A1c values. Further, our research team recently conducted a secondary analysis of three large, randomized clinical smoking intervention trials examining cessation rates among African American participants with self-reported diabetes. Our analyses concluded that there was a doubling of quit rates among persons with diabetes as compared to those with no diabetes. ${ }^{31}$ Thus, results of these recent investigations suggested that persons with diabetes may be highly responsive to cessation efforts and that diabetes management may not be impacted negatively when cessation is targeted.

Because the knowledge, attitudes, beliefs, and preferences of smokers facilitate maximum receptivity to programs, these are important considerations when developing effective cessation interventions. ${ }^{32}$ Qualitative research is well-suited to provide in-depth answers to these complex issues and may suggest ways to intervene with a target group successfully. Further, focus groups are well-suited for this study because the collaborative effort of the groups stimulated participant discussion of a topic about which they did not think about individually. ${ }^{33}$ Thus, this qualitative study employed focus groups and a short survey to assess cigarette use patterns, perceived health effects of smoking, preferences for treatment, and attitudes toward cessation interventions among urban, African American smokers with type 2 diabetes.

\section{Methods}

Participants. Eligible participants were 18 years or older, African American, selfreported as having diabetes and smoked five or more cigarettes per day. Exclusion 
criteria included variables that would hinder participation in a group discussion or ability to be contacted. These criteria included homelessness, marked inappropriate affect or behavior, or impaired cognition. Participants also were excluded if they had previously participated in any prior formal smoking cessation program.

Procedures. The research protocol was approved by the University of Kansas Medical Center's Human Subjects Committee prior to implementation. Participants were recruited at a community health center (Swope Health Services) that serves under- and uninsured, predominantly African American, patients. Flyers were posted in several clinics including Internal Medicine, Nutrition, Podiatry, and the patient pharmacy. In addition, a research assistant sat at a booth and handed out flyers to interested participants in the lobby of the health center. The one-page recruitment flyer was designed to recruit African American adults who had diabetes, smoked cigarettes, and were interested in participating in a group discussion about smoking and diabetes. Potential participants who responded to the flyer were screened for eligibility by phone or in the health center lobby.

Four focus groups were held over a twoweek period. A clinical psychologist, with focus group facilitation training, moderated the groups. Three research assistants, one of whom was a representative of the Swope community, greeted participants, offered snacks, completed forms, video- and audiorecorded the groups, and distributed incentives. All participants provided both written and verbal informed consent to be audio- and video-recorded.

Following the consent procedure, participants completed a brief survey documenting demographic, tobacco-related and diabetes-specific health information. The assistant moderator read all survey questions aloud while a research assistant circulated to assist individual participants as needed. The focus groups were led using a moderator's guide developed specifically for this study. Researchers with experience in smoking cessation, diabetes, and focus group methodology developed the guide. ${ }^{34,35}$ The moderator followed a semi-structured interview format using open-ended questions to stimulate discussion about knowledge, attitudes, and beliefs about smoking and diabetes. Table 1 displays example questions from the moderators guide.

During each focus group, the moderator probed participants' responses and encouraged all members to participate. The group discussions lasted approximately 90 minutes. After the groups ended, the research assistant collected a list of participants' medications in an attempt to corroborate their self-reported diagnosis of diabetes. After medications were recorded,

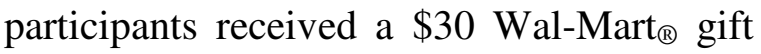
card as compensation for their travel cost, time, and effort. Data collection stopped after data saturation had occurred for the majority of our topic areas (i.e., no new data would be found by conducting further focus groups). ${ }^{33}$

Data analysis. Survey data were doubleentered and range checks were performed. Descriptive statistics were computed using SPSS Version 13.0 (SPSS Inc., Chicago, IL). Audio-recordings of the focus groups were transcribed verbatim by a contracted professional transcription service. The focus group moderator proofread each transcript and compared them to the video-recordings to check for completeness and accuracy. Three independent coders deductively categorized transcripts by hand into six major topic areas using initial codes developed by the research team based on the focus group moderator's guide. Coders then coded transcripts by hand within each major 
Table 1. Sample questions from moderators guide.

\begin{tabular}{|l|l|}
\hline Topics & Questions \\
\hline $\begin{array}{l}\text { Attitudes toward smoking (positives and } \\
\text { negatives). }\end{array}$ & $\begin{array}{l}\text { What do you enjoy about smoking? What are } \\
\text { some of the positive/negative things about } \\
\text { smoking? }\end{array}$ \\
\hline $\begin{array}{l}\text { Beliefs and knowledge about smoking and } \\
\text { diabetes. }\end{array}$ & $\begin{array}{l}\text { Are there any problems associated with } \\
\text { cigarette smoking that smokers with diabetes } \\
\text { might face more than other people? }\end{array}$ \\
\hline $\begin{array}{l}\text { Change in smoking since diagnosed with } \\
\text { diabetes. }\end{array}$ & $\begin{array}{l}\text { Has anything about your smoking changed } \\
\text { since you were diagnosed with diabetes? }\end{array}$ \\
\hline Prior experiences with quitting. & $\begin{array}{l}\text { For those of you who are thinking about giving } \\
\text { up cigarettes, what are some reasons you } \\
\text { would like to quit smoking? Tell us about the } \\
\text { methods you have tried to help you quit } \\
\text { smoking in the past and how it went. }\end{array}$ \\
\hline $\begin{array}{l}\text { Beliefs and opinions about quitting (e.g., } \\
\text { different for diabetic patients). }\end{array}$ & $\begin{array}{l}\text { How might quitting be different for people } \\
\text { with diabetes? }\end{array}$ \\
\hline Treatment preferences. & $\begin{array}{l}\text { Tell us if you believe that a stop smoking } \\
\text { program should be offered as part of your } \\
\text { diabetes treatment program or should it be kept } \\
\text { separate and what should include? }\end{array}$ \\
\hline
\end{tabular}

topic area using an inductive approach whereby categories and concepts emerge from the text and are linked together. ${ }^{33}$ This approach allowed the data to represent itself.

A fourth independent researcher crosschecked inductive codes and identified minor discrepancies in the coding and varying terminology used by each coder to describe the same content. Cross-checking codes provided a measure of how well the data were indexed and, thus, gave a qualitative measure of inter-coder reliability. ${ }^{36}$ Overall, the independent researcher found high inter-coder reliability and identified major themes within the codes. The research team then met as a group to discuss the major themes and to address any discrepancies. Ten major saturated themes emerged across coders, as well as several unsaturated topics and themes that provided avenues for future research.

\section{Results}

Participants. Of the 59 people who responded to the study flyers, 50 were eligible to participate. Reasons for exclusion were not having diabetes $(\mathrm{n}=2)$, being homeless or living in a treatment facility ( $\mathrm{n}$ $=4$ ), and previous participation in smoking cessation groups $(n=3)$. Of those eligible, 25 did not show for their scheduled focus group and efforts to reschedule were not successful. Thus, the final sample included 25 participants.

As detailed in Table 2, participants were on average middle-aged $(\mathrm{M}=48.5 \pm 10.2$ years) and female (60\%). Most had at least a high school level education (32\%) or some college $(36 \%)$, were divorced $(36 \%)$ or single (24\%), and most did not have any health insurance $(73 \%)$. Participants had been diagnosed with diabetes for an average of 12.2 years, and the average age at diabetes diagnoses was 36.8 years (SD \pm 13.33). Forty-four percent used insulin 
to manage their diabetes. The average number of cigarettes smoked per day was 20.9 (SD \pm 12.54$)$; participants began smoking at age $18(\mathrm{SD} \pm 9.46)$ and reported an average of three 24-hour quit attempts (M $\left.=3.16, \mathrm{SD}_{ \pm} 6.12\right)$ in the last year.

Table 2. Demographics characteristics of sample $(\mathrm{n}=25)$.

\begin{tabular}{|c|c|}
\hline Demographics & Number (\%) \\
\hline Mean age & 48.5 \\
\hline Female & $15(60)$ \\
\hline \multicolumn{2}{|l|}{ Education: } \\
\hline 10-12 years, no diploma & $6(24)$ \\
\hline Diploma/GED & $8(32)$ \\
\hline Vocational & $1(4)$ \\
\hline Some college & $9(36)$ \\
\hline College degree & $1(4)$ \\
\hline \multicolumn{2}{|l|}{ Marital status: } \\
\hline Married & $1(4)$ \\
\hline Widowed & $1(4)$ \\
\hline Separated & $5(20)$ \\
\hline Single/Never married & $6(24)$ \\
\hline Divorced & $9(36)$ \\
\hline Living with someone & $2(8)$ \\
\hline \multicolumn{2}{|l|}{ Diabetes management: } \\
\hline Diet/Exercise & $14(56)$ \\
\hline Oral agents & $16(64)$ \\
\hline Insulin & $11(44)$ \\
\hline No health insurance & $19(76)$ \\
\hline
\end{tabular}

Tobacco-related variables. As detailed in Table 3, many participants $(68 \%)$ were considering to quit smoking in the next six months and $60 \%$ had cut down the number of cigarettes smoked to lower their health risks. Further, they moderately were motivated $(\mathrm{M}=6.04, \mathrm{SD} \pm 2.59)$ and confident regarding quitting $(\mathrm{M}=5.60, \mathrm{SD} \pm 3.4)$. Also, most participants moderately were concerned about the effects of smoking $(\mathrm{M}=6.23, \quad \mathrm{SD} \pm 3.73)$ and weight gain $(\mathrm{M}=5.16, \quad \mathrm{SD} \pm 4.0)$ on their diabetes complications should they quit smoking. When asked about prior quit attempts, participants reported that they relied on their own will power (76\%), spirituality $(62 \%)$, and support from family and friends to help them quit $(32 \%)$. Fewer had used formal treatment $(4 \%)$ or nicotine replacement therapy $(32 \%)$ or buproprion $(4 \%)$ in their prior quit attempts.

Table 3. Smoking characteristics $(n=25)$.

\begin{tabular}{|c|c|}
\hline Variable & $\begin{array}{c}\text { Mean (SD) } \\
\text { or Number } \\
(\%)\end{array}$ \\
\hline $\begin{array}{l}\text { Age at diabetes diagnoses } \\
\text { (years) }\end{array}$ & $36.8(13.33)$ \\
\hline Cigarettes smoked per day & $20.9(12.5)$ \\
\hline Age started smoking & $18.3(9.5)$ \\
\hline Years as a smoker & $26.8(11.3)$ \\
\hline $\begin{array}{l}\text { 24-hour quit attempts in the } \\
\text { past year }\end{array}$ & $3.2(6.1)$ \\
\hline Weight concern (1-10 scale) & $5.16(4.0)$ \\
\hline Lives with smoker & $15(60 \%)$ \\
\hline $\begin{array}{l}\text { Concern about effects of } \\
\text { smoking on diabetes ( } 0-10 \\
\text { scale) }\end{array}$ & $6.23(3.73)$ \\
\hline Motivation to quit (1-10 scale) & $6.0(2.6)$ \\
\hline Confidence to quit (1-10 scale) & $5.6(3.4)$ \\
\hline $\begin{array}{l}\text { Number of minutes awake } \\
\text { prior to first cigarette: } \\
\qquad 5 \text { minutes } \\
6-30 \text { minutes } \\
31-60 \text { minutes } \\
>60 \text { minutes }\end{array}$ & $\begin{array}{c}13(52 \%) \\
5(20 \%) \\
6(24 \%) \\
1(4 \%) \\
\end{array}$ \\
\hline Plans to quit in next 30 days & $9(36 \%)$ \\
\hline Plans to quit in next 6 months & $17(68 \%)$ \\
\hline $\begin{array}{l}\text { Ever switched brands for } \\
\text { health reasons }\end{array}$ & $13(52 \%)$ \\
\hline $\begin{array}{l}\text { Ever switched brands to lower } \\
\text { smoking risks }\end{array}$ & $15(60 \%)$ \\
\hline $\begin{array}{r}\text { Prior cessation aids used: } \\
\text { Nicotine Gum } \\
\text { Nicotine Patch } \\
\text { Nasal Spray } \\
\text { Nicotine Inhaler } \\
\text { Nicotine Lozenge } \\
\text { Buproprion }\end{array}$ & $\begin{array}{l}7(28 \%) \\
8(32 \%) \\
1(4 \%) \\
1(4 \%) \\
1(4 \%) \\
1(4 \%)\end{array}$ \\
\hline $\begin{array}{l}\text { Aids used during prior } \\
\text { cessation attempts: } \\
\text { "Cold turkey"/On my own } \\
\text { Prayer/God/Spirituality } \\
\text { Support from family/friends } \\
\text { Support group or clinic }\end{array}$ & $\begin{array}{c}19(76 \%) \\
16(64 \%) \\
8(32 \%) \\
1(4 \%) \\
\end{array}$ \\
\hline
\end{tabular}




\section{Thematic Analyses By Topics}

Ten unique themes emerged across focus groups and reached saturation (see Table 4).

Attitudes toward smoking. The most commonly reported reason to continue smoking was to control weight through appetite suppression. Many participants also expressed the belief that smoking helped them to control their blood sugar level. They also reported that smoking helped them cope with high levels of stress related to their diabetes self-care and life stress (e.g., financial difficulties, child care). Alternately, participants reported that the most important reasons to quit smoking were the cost and the known health consequences.

Examples of participant comments were:

$>$ “As long as I am smoking, I won't be feeding myself all the time." (male participant)

$>$ "Sometimes if I get upset at somebody, like one of my kids, I light a cigarette that's how I calm down." (female participant)

$>$ "If I have five dollars and I know I need gas, I think, "well, maybe I could put three dollars in the gas tank and take this two dollars and buy some cigarettes'...I want to quit to save money." (female participant)

Beliefs and knowledge about smoking and diabetes. Most participants endorsed the belief that smoking would increase their risk of diabetes-related negative health outcomes. However, few participants were able to articulate their understanding of the mechanism by which smoking and diabetes might interact to elevate diabetes-related risk factors.

Examples of participant comments were:

$>$ "I'm not clear on the connection between smoking and diabetes, but they say it makes diabetes worse." (female participant)
$>$ "Diabetes already decreases our circulation, but smoking makes that even worse because we are reducing the amount of oxygen that flows through our bodies. I think that is why we start to lose feeling in our fingers and toes." (female participant)

$>$ "I've got diabetes, heart disease, high cholesterol, and I smoke. I shouldn't smoke and the doctors even say I need to quit smoking cigarettes, but I keep telling them I don't want to." (male participant)

Participants believed that smoking decreased their appetite and that quitting smoking would result in weight gain, a known hazard to their diabetes management. Comments included:

> "When I found out that I had diabetes, I lost weight, but then once the medicine kicked in, I gained weight. Then, I started smoking again so that I wouldn't eat as much." (female participant)

$>$ "Since I'm a diabetic I feel that I have to watch my weight, so I don't eat that much. That is why I'm scared to stop smoking. I'll gain weight." (female participant).

Change in smoking since diagnosed with diabetes. Most participants endorsed making a smoking quit attempt since being diagnosed with diabetes. However, they explained that cessation resulted in the experience of additional stress and difficulty focusing on their diabetes self-care. Because our inclusion criteria included being a current smoker, it is unknown whether other persons with diabetes who have had success in quitting met with these same barriers yet were able to overcome them.

Examples of participant comments were:

$>$ "When I was diagnosed with diabetes, I had already been smoking for 30 years. I know that I should have quit before then, but now I am under so much more 
Table 4: Focus group topics and themes.

\begin{tabular}{|c|c|}
\hline Topics & Themes \\
\hline $\begin{array}{l}\text { Attitudes toward smoking (positives and } \\
\text { negatives). }\end{array}$ & $\begin{array}{l}\text { Most common reasons for smoking were to } \\
\text { cope with stress or negative emotions } \\
\text { (calming mechanism) or to control or lose } \\
\text { weight. } \\
\text { Most common reasons to stop smoking } \\
\text { were the health consequences and cost. }\end{array}$ \\
\hline $\begin{array}{l}\text { Beliefs and knowledge about smoking and } \\
\text { diabetes. }\end{array}$ & $\begin{array}{l}\text { Participants believed that smoking } \\
\text { increased their risk for all health outcomes, } \\
\text { though there was not a clear understanding } \\
\text { of how (some discussion of ties to insulin } \\
\text { levels in blood, but this is unclear). } \\
>\text { Participants believed smoking decreased } \\
\text { their appetite. They also thought that } \\
\text { quitting makes you gain weight and that it } \\
\text { would negatively affect diabetes. }\end{array}$ \\
\hline $\begin{array}{l}\text { Change in smoking since diagnosed with } \\
\text { diabetes. }\end{array}$ & $\begin{array}{l}\text { Since diagnosis, many participants have } \\
\text { attempted to quit, but with no success. } \\
\text { Many participants voiced concern that } \\
\text { quitting will result in worsened diabetes } \\
\text { self-management. }\end{array}$ \\
\hline Prior experiences with quitting. & $\begin{array}{l}\text { Most participants had tried to quit, with the } \\
\text { most common method being "cold turkey." } \\
\text { Few pharmacotherapy products were } \\
\text { discussed, but participants agreed that } \\
\text { insurance benefits should cover cessation } \\
\text { products. }\end{array}$ \\
\hline Beliefs and opinions about quitting. & $\begin{array}{l}\text { Most participants wanted to quit and } \\
\text { believed it was important to quit, but were } \\
\text { not motivated to quit or confident they } \\
\text { could achieve cessation. }\end{array}$ \\
\hline Treatment preferences. & $\begin{array}{l}>\text { Participants were undecided on whether } \\
\text { persons with diabetes should have a } \\
\text { separate smoking cessation program from } \\
\text { other smokers or if diabetes care should be } \\
\text { kept separate. } \\
>\text { Ideas about what should be included in a } \\
\text { smoking cessation program and barriers to } \\
\text { that program are mixed and mirror a } \\
\text { heterogeneous group of smokers. }\end{array}$ \\
\hline
\end{tabular}

stress, and now I have gained more weight too. I know I need to quit, but now it is even more of a crutch for me." (female participant)
"I'm more aware now since I've been diagnosed with diabetes, I'm much more aware of how much I smoke." (male participant) 
$>$ "Well, I smoke more because it seems like there's an urge to smoke more since I'm taking pills. It [diabetes] is kind of threatening." (male participant)

$>$ "As soon as I leave here, I am going to smoke a cigarette. What am I going to stop smoking for? I am already messed up anyway." (male participant)

Prior experience with quitting. Most participants had tried to quit in the past (most using the "cold turkey" method) and believed that it is important for them to quit. Few had tried nicotine replacement therapy or bupropion to quit. The few who had tried found it helpful, therefore, they focused their discussion on their disappointment that insurance did not cover these cessation aids or that they did not have insurance. Finally, participants were unaware of the existence of state-funded cessation services (e.g., quit lines).

Examples of participant comments were:

$>$ "The pill (bupropion) mellows you out. Someone could say something very negative to me and it wouldn't bother me. I was more pleasant. So, yeah, to me, if I had it to do all over again and I could ever get that pill, yes, I would go back." (female participant)

$>$ "The last time I was in the hospital, I was in a diabetic coma. They gave me the nicotine patch, but because I do not have insurance, I could not keep using it." (female participant)

$>$ "I have made an honest effort to quit smoking, but I tried to get the patch along with my medicine. Since I do not have insurance and I am already using the hospital discount to get my medicine, I can't get the patch." (female participant)

Beliefs and opinions about quitting. Most subjects endorsed the belief that it is important for them to quit for their health, particularly given their diabetes, but were not ready to make that change nor confident that they could do so.

Examples of participant comments were:

$>$ "...I have to work on one thing at a time, me, and I'd rather work on my diabetes. I know smoking's not good for us at all, so I have to focus on my diabetes, you know first, and then as time goes by I can wean myself off of smoking, but I just can't go with the whole thing. Huhhuh, it's too much on me." (female participant)

$>$ "I've got diabetes, heart disease, high cholesterol, and I smoke. I shouldn't smoke and the doctors even say I need to quit smoking cigarettes, but I keep telling them I can't."(male participant)

$>$ "When I was diagnosed with diabetes, I had already been smoking for 30 years. I know that I should have quit before then, but now I am under so much more stress, and now I have gained more weight too. I know I need to quit, but now it is even more of a crutch for me." (female participant)

$>$ "Since we have diabetes, we would have so much more to gain by quitting smoking." (female participant)

Treatment preferences. Participants had mixed views on whether persons with diabetes should have a separate smoking cessation program from non-smokers with diabetes and whether smoking should be targeted if diabetes self-management is not under good control. However, most commented that they did not want their physicians to provide cessation services in addition to their diabetes care. Participants also voiced a variety of preferences for cessation treatment services including individual and group counseling, medication, 24-hour helplines, and support groups. The ideas endorsed mirror those typically requested by smokers.

Examples of participant comments were: 
$>$ "The smoking group should be separate from the diabetes group because we have different problems related to diabetes." (female participant)

$>$ "I would prefer group-type counseling and it would be nice if you could offer medications or the patch to help us stop smoking." (female participant)

$>$ "I would like to have a support group like this focus group. That way everyone would get to exchange personal stories about what worked and didn't work. It makes me feel less alone when I hear about what other people are going through." (female participant)

\section{Discussion}

Our qualitative findings offer insights for understanding and developing intervention strategies for smoking cessation among African American adults with diabetes. In general, our participants expressed a desire to quit smoking, but voiced concerns regarding the potential impact of quitting on their diabetes self-management. Specifically, participants were concerned about the impact of quitting on their stress level and cessation-related weight gain. In addition, several participants noted that they had increased their smoking level after receiving the diagnosis of diabetes.

The association between diabetes diagnosis and increased smoking behavior and decreased motivation to quit needs to be determined through further investigation. However, if smokers are at risk for an increase in smoking following diabetes diagnoses, then using the diagnostic visit as a potentially "teachable moment" to introduce the importance of cessation and providing treatment options may be an important preemptive strategy.

Using cigarette smoking to cope with stress and weight gain are consistent themes found in the smoking literature. However, the stress management properties of smoking may be particularly important in our sample given their substantial sources of life stress (e.g., poverty status, ethnic minority, no health insurance, and diabetes). As such, participants overwhelmingly agreed with one participant when she mentioned that "...without stress there would be no need for smoking." Previous research has focused on the stress inherent with the self-management requirements of diabetes and the negative impact of stress on diabetes care. Thus, although most diabetes programs include instruction on the importance of stress management in diabetes self-care, it is clear that if we are to address the devastating health effects of the combination of diabetes and smoking, providers must offer patients alternative stress management strategies.

Our participants frequently mentioned continuing to smoke to prevent weight gain and a few mentioned a noticeable association between smoking and glycemic control (in both "positive" and "negative" directions). Although participants recognize that weight gain may have a negative impact on their diabetes self-care, they did not seem to have the same level of awareness regarding the negative consequences of the combination of diabetes and smoking. One participant reported that she quit smoking but that when she gained weight, she returned to smoking to decrease her appetite so that she might be in more control of her eating habits.

Weight gain following cessation is indeed a risk. Iino and colleagues ${ }^{37}$ found that in a sample of smokers with diabetes who quit, body weight at six months increased by approximately three pounds. This increase is less of a health risk than the alternative of continuing smoking. However, the weight gain is a risk with which individuals with diabetes appear to be concerned, possibly because it is physically noticeable. 
It is unclear whether providers address the risks of smoking in relation to weight gain with patients. Although this study was not designed to address this important concept, future studies are encouraged to explore physician attitudes toward smoking cessation and weight gain among smokers with diabetes. In addition, there were mixed experiences from participants on whether smoking may improve glycemic control or if glucose levels were higher following smoking a cigarette. Future research is needed to investigate the relationship between smoking and the acute impact on glycemic control.

Limitations. There are several limitations to this study that prevent generalizing results to all African American smokers with diabetes. Although we recruited a sufficient number of participants and reached saturation in our qualitative analyses, our sample size was small.

Our difficulty recruiting and retaining smokers with diabetes may be reflective of the lack of prioritization placed on cessation among those with diabetes. Although our recruitment flyers stressed that smokers did not need to be interested in smoking cessation to attend, it may be that some smokers may have felt uncomfortable attending a group focused on smoking. It also may be that our recruitment challenges may reflect a more favorable picture. That is, it is possible that smokers with diabetes are quitting.

Recent population-based studies suggested that the prevalence of smoking among patients with diabetes mirrors that of the general population. However, our study site, Swope Health Services, has been the site of two large, randomized trials enrolling African American smokers. Thus, it may be that the smoking prevalence among the subpopulation of patients using the Swope Health Center, our participants included, is lower than the national average. One follow-up approach might be to conduct qualitative research with persons with diabetes at other sites and with those who were able to quit smoking successfully.

A second limitation pertains to the exploratory nature of this project. Our focus groups were designed to be open-ended and exploratory. By using this design, we touched on several different topics and addressed the question of what to do about smokers with diabetes, and in this case, among the African American population. However, exploratory focus groups tend to ask more questions than they answer, as was the case for our groups.

From our review of the literature, there is a dearth of information about smokers with diabetes and researchers only now have begun to understand how smoking is seen by these individuals and the role it plays in their lives. Before creating a smoking cessation program targeting this population, further research is needed to understand the complexities of ethnicity, smoking, stress, weight gain, and glycemic control among smokers with diabetes.

Provider recommendations. Our qualitative analyses provided evidence that among lower income, African Americans with diabetes, smoking cessation assistance is wanted and needed by patients, but may presented unique challenges. Smoking cessation among persons with diabetes may be more difficult than for the general population due to their beliefs about the potential negative health consequences of cessation on their diabetes. Therefore, smokers with diabetes may need tailored education about the health consequences of both smoking and cessation on their diabetes.

Though our participants knew superficially that smoking increased their risk of various health outcomes, they were limited in their understanding of why or how this might occur. Some participants 
acknowledged that smoking influences insulin levels, but this was by no means a majority of participants and those who mentioned it could not explain further.

Although our participants were unanimous in endorsing that smoking cessation care should be from a different provider than their diabetes care providers, the American Diabetic Association ${ }^{38}$ recommends that diabetes care providers routinely assess and document smoking status; advise individuals with diabetes not to start smoking and provide cessation counseling as a routine component of diabetes care among smokers. Further, among patients interested in quitting, the guidelines recommended that diabetes care providers recommend nicotine replacement therapy and/or intensive counseling and

\section{References}

${ }^{1}$ Centers for Disease Control and Prevention. Cigarette smoking among adults-United States, 2000. MMWR Morb Mortal Wkly Rep 2002; 51:642-645.

${ }^{2}$ U.S. Department of Health and Human Services. Tracking Healthy People 2010. Washington, DC: U.S. Government Printing Office, November 2000.

${ }^{3}$ Centers for Disease Control and Prevention. Cigarette smoking among adults-United States, 1997. MMWR Morb Mortal Wkly Rep 1999; 48:993-996.

${ }^{4}$ Centers for Disease Control and Prevention. Disparities in premature deaths from heart disease-50 States and the District of Columbia, 2001. MMWR Morb Mortal Wkly Rep 2004; 53:121-125.

${ }^{5}$ U.S. Department of Health and Human Services. Tobacco Use Among U.S. Racial/Ethnic Minority Groups - African Americans, American Indians and Alaskan Natives, Asian Americans and Pacific Islanders, and Hispanics. A Report of Surgeon General. Atlanta, Georgia: U.S. Department of Health and Human provide follow-up assessment on cessation. The ADA guidelines also recommend that all diabetes health providers be trained regarding these recommendations and that systems to implement these guidelines are incorporated into clinical diabetes care. ${ }^{38}$

Despite these guideline recommendations, most participants chose "cold turkey" in their prior quit attempts. This finding suggested that participants either do not understand the benefits of nicotine replacement therapy and counseling for cessation or that practitioners are not following guideline recommendations. Future studies should assess the quality of cessation care provided to smokers with diabetes and investigate the possible impact of utilizing a secondary provider solely for cessation care.

Services, Centers for Disease Control and Prevention, National Center for Chronic Disease Prevention and Health Promotion, Office on Smoking and Health, 1998.

6 American Cancer Society. Cancer Facts and Figures for African Americans 20052006. New York, NY: American Cancer Society, Inc, 2005.

${ }^{7}$ Resnicow K, Futterman R, Weston RE, et al. Smoking prevalence in Harlem, New York. Am J Health Promot 1996;10:343346.

${ }^{8}$ Centers for Disease Control and Prevention. Cigarette smoking among adults-United States, 2001. MMWR Morb Mortal Wkly Rep 2003; 52:953-956.

9 Ahluwalia JS, McNagny SE. Smoking prevalence and desire to quit in inner-city African American walk-in clinic patients. Clin Res 1993;41:752A.

${ }^{10}$ Hahn LP, Folsom AR, Sprafka JM, Norsted SW. Cigarette smoking and cessation behaviors among urban blacks and whites. Public Health Rep 1990; 105:290-295. 
${ }^{11}$ Novotny TE, Warner KE, Kendrick JS, Remington PL. Smoking by blacks and whites: Socioeconomic and demographic differences. Am J Public Health 1988; 78:1187-1189.

${ }^{12}$ Schoenborn CA, Adams PF, Barnes PM, Vickerie JL, Schiller JS. Health behaviors of adults: United States, 1999-2001. Vital Health Stat 2004; 10:1-79.

${ }^{13}$ Romano PS, Bloom J, Syme SL. Smoking, social support, and hassles in an urban African-American community. Am J Public Health 1991;81:1415-1422.

${ }^{14}$ Joseph AM, Norman SM, Ferry LH, et al. The safety of transdermal nicotine as an aid to smoking cessation in patients with cardiac disease. N Engl J Med 1996; 335:1792-1798.

${ }^{15}$ Harris RE, Zang EA, Anderson JI, Wynder EL. Race and sex differences in lung cancer risk associated with cigarette smoking. Int J Epidemiol 1993; 22:592599.

${ }^{16}$ Gillum RF. Risk factors for stroke in blacks: A critical review. Am J Epidemiol 1999; 150:1266-1274.

${ }^{17}$ Rosenberg L, Palmer JR, Rao RS, AdamsCampbell LL. Risk factors for coronary heart disease in African American women. Am J Epidemiol 1999; 150:904-909.

${ }^{18}$ Liao Y, McGee DL, Cooper RS. Prediction of coronary heart disease mortality in blacks and whites: Pooled data from two national cohorts. Am J Cardiol 1999; 84:31-36.

${ }^{19}$ National Institute of Diabetes and Digestive and Kidney Diseases. National Diabetes Fact Sheet: General Information and National Estimates on Diabetes in the United States, 2005. Bethesda, MD: U.S. Department of Health and Human Services, National Institutes of Health, 2005

${ }^{20}$ Ganda OP. Pathogenesis of macrovascular disease in the human diabetic. Diabetes 1980; 29:931-942.
${ }^{21}$ Muhlhauser I. Cigarette smoking and diabetes: An update. Diabet Med 1994; 11:336-343.

${ }^{22}$ Ford ES, Newman J. Smoking and diabetes mellitus. Findings from 1988 Behavioral Risk Factor Surveillance System. Diabetes Care 1991; 14:871-874.

${ }^{23}$ Muhlhauser I, Bender R, Bott U, et al. Cigarette smoking and progression of retinopathy and nephropathy in type 1 diabetes. Diabet Med 1996; 13:536-543.

${ }^{24}$ Tesfaye S, Stevens LK, Stephenson JM, et al. Prevalence of diabetic peripheral neuropathy and its relation to glycaemic control and potential risk factors: The EURODIAB IDDM Complications Study. Diabetologia 1996; 39:1377-1384.

${ }^{25}$ Haire-Joshu D, Glasgow RE, Tibbs TL. Smoking and diabetes. Diabetes Care 1999; 22:1887-1898.

${ }^{26}$ Ardron M, MacFarlane IA, Robinson C, van Heyningen C, Calverley PM. Antismoking advice for young diabetic smokers: Is it a waste of breath? Diabet Med 1988; 5:667-670.

${ }^{27}$ Canga N, De Irala J, Vara E, Duaso MJ, Ferrer A, Martinez-Gonzales MA. Intervention study for smoking cessation in diabetic patients: A randomized controlled trial in both clinical and primary care settings. Diabetes Care 2000; 23:1455-1460.

${ }^{28}$ Fowler PM, Hoskins PL, McGill M, Dutton SP, Yue DK, Turtle JR. Antismoking programme for diabetic patients: The agony and the ecstasy. Diabet Med 1989; 6:698-702.

${ }^{29}$ Sawicki PT, Didjurgeit U, Muhlhauser I, Berger M. Behaviour therapy versus doctor's anti-smoking advice in diabetic patients. J Intern Med 1993; 234:407-409.

${ }^{30}$ Hokanson JM, Anderson RL, Hennrikus DJ, Lando HA, Kendall DM. Integrated tobacco cessation counseling in a diabetes self-management training program: A randomized trial of diabetes and reduction 
of tobacco. Diabetes Educ 2006; 32:562570.

${ }^{31}$ Thomas JL, Ahluwalia JS, Choi W, et al. Smoking cessation in African Americans with diabetes: Secondary analyses of three randomized trials. Presentation at the Society for Research on Nicotine and Tobacco, Prague, Czech Republic, 2005.

${ }^{32}$ Becker DM, Hill DR, Jackson JS, Levine DM, Stillman FA, Weiss SM. (Eds.) Health Behavior Research in Minority Populations: Access, Design, and Implementation. (NIH publication \# 922965.) Bethesda, MD: National Institutes of Health, 1992.

${ }^{33}$ Bernard HR. Research Methods in Anthropology: Qualitative and Quantitative Approaches. 3rd Edition. Walnut Creek, CA: Altamira Press, 2002.
${ }^{34}$ Kreuger RA. Developing Questions for Focus Groups. Thousand Oaks, CA: Sage Publications, 1998.

${ }^{35}$ Fern E. Advanced Focus Group Research. Thousand Oaks, CA: Sage Publications, 2001.

${ }^{36}$ Stewart A. The Ethnographer's Method. Thousand Oaks, CA: Sage Publications, 1998.

${ }^{37}$ Iino $\mathrm{K}$, Iwase $\mathrm{M}$, Tsutsu N, Iida M. Smoking cessation and glycaemic control in type 2 diabetic patients. Diabetes Obes Metab 2004; 6:181-186.

${ }^{38}$ American Diabetic Association. Smoking and diabetes. Diabetes Care 2002; 25(S1):80-81.

Keywords: smoking, diabetes mellitus, African Americans, qualitative research 